\title{
Investigating the Formation of Service Supply Chains
}

\author{
ABSTRACT \\ Existing research on service supply chains assumes the existence of an \\ established and mature chain. Empirical or conceptual insights into service \\ supply chain formation are therefore limited. The initial formation of a service \\ supply chain, however, is suspected to determine its future performance. It is \\ therefore of significant academic and managerial value to understand how and \\ why service supply chains are formed, and how this process is coordinated. \\ Drawing on an exploratory case study set in the management consulting \\ industry, the inductive theory-building process underlying this study culminates \\ in propositions and a conceptual model that provides a distinct understanding of \\ service supply chain formation and the coordination mechanisms utilized within \\ each stage. This study contributes to the service science, service supply chains, \\ and service sourcing literatures, outlines managerial implications, and proposes \\ future research directions.
}

Keywords: Consulting, Coordination, Formation, Services, Supply Chain Paper type: Research paper 


\section{Introduction}

Service supply chains are distinct components of larger value networks that consist of one or multiple service providers who engage with one or multiple service customers for a common purpose. While service supply chains emerge as an important and growing research field (Sengupta, Heiser, \& Cook, 2006; Giannakis, 2010) and, as such, represent a "worthy topic [emerging] from disciplinary priorities" (Tracy, 2010, p. 840), empirical and conceptual studies on service supply chains to date have rarely been conducted "in an academic and rigorous way" (Sampson \& Spring, 2012, p. 3).

Service supply chains are traditionally perceived as distinct from goods-centric or 'product' supply chains (Ellram, Tate, \& Billington, 2004). Thus, attempts to transfer insights gained from 'product' to service supply chains have not been particularly successful, due to their focus on service providers and omission of service customers from the inquiry. For example, Akkermans and Vos (2003) examine the bullwhip effect in a telecommunications service supply chain, while Frohlich and Westbrook (2002) compare supply chain integration in the manufacturing and service sector. These 'goods-centric' attempts stand in contrast to the current understanding of economic exchange rooted in the service-dominant (SD) logic (Vargo \& Lusch, 2004). After applying a SD logic lens to existing service supply chain research, scholars highlighted that existing work in the field is conceptually and theoretically insufficient, as well as empirically limited (Lusch, Vargo, \& Tanniru, 2010; Breidbach, Reefke, \& Wood, 2011). Investigating the roles of customers in service supply chains has since been acknowledged as a key research priority for the field (Maull, Geraldi, \& Johnston, 2012). 
The second shortcoming of previous studies is their explicit or implicit focus on existing, mature service supply chains that operate in a steady state. The dynamics of the initial formation, or transient state, have therefore been left unexplored, and represent a significant research opportunity. Scholars previously suspected that the structure of a service supply chain, and consequently its ability to perform, is determined at its initial formation (Walsh \& Wellman, 2000; Walsh, Wellman, \& Ygge, 2000). However, insights into why service supply chains are initially formed, or how this process may best be coordinated, are unavailable to date.

In this work, we address the existing conceptual and empirical gaps in knowledge by exploring the formation of service supply chains, as well as the use of coordination mechanisms therein. We present findings from an exploratory case study conducted in the management consulting industry, where we collected data from both the service providers and the customer. This approach allows us to extend the unidirectional focus on service providers which has not only dominated much of the extant literature but has also been criticized (Heinonen et al., 2010). As such, this work contributes to the nascent literature at the intersection of service science, service supply chains, and service sourcing, and aids in the development of theory and practice through a set of research propositions, associated managerial guidelines, and future research opportunities. 


\section{Literature review}

\section{Defining service supply chains}

Three distinct schools of thought previously attempted to define service supply chains. First, the oldest and most prominent is the demarcation school, which differentiates between 'services' and goods-centric economic exchange and, consequently, perceives service supply chains as distinct from 'traditional' goods-centric supply chains. For example, Ellram et al. (2004) argue that service supply chains rely on a flow of information rather than a flow of physical goods. Akkermans and Vos (2003) argue that the unique characteristics of services like customer interaction, simultaneity of production and consumption, intangibility, perishability, and labor intensity, are elements unique to service supply chains. These scholars thereby followed a well-established idea from the service marketing literature that, though not without criticism (Lovelock \& Gummesson, 2004), has long argued that 'services' should be delineated from 'goods' by using the criteria of intangibility, heterogeneity, inseparability, and perishability (Zeithaml, Parasuraman, \& Berry, 1985). Finally, some scholars within the demarcation school highlight the distinctiveness of the 'human element'. The argument persists that, in contrast to goods-centric supply chains, service supply chains hold no finished goods inventory but are constrained by the availability of skilled labor (Anderson, Morrice, \& Lundeen, 2006; Sengupta et al., 2006). Therefore, service supply chains are often discussed in the context of professional services like consulting (Anderson et al., 2006), which rely on human labor, rather than physical goods (Lusch et al., 2010).

Second, expansion scholars advocate that service supply chains enhance “manufacturing organizations' ability to compete" (Youngdahl \& Loomba, 2000, p. 329). While this school of thought also differentiates between goods and services, an individual service is merely seen as an extension or enhancement of a traditional goods-centric supply 
chain. This notion is similar to 'servitization', where 'product-service-systems' result in additional value adding capabilities (Vandermerwe \& Rada, 1988). For example, Baltacioglu, Ada, Kaplan, Yurt, and Kaplan (2007) argue that services are part of goods-centric supply chains, making it unnecessary to differentiate between goods and service supply chains, and implicitly negate their existence.

Finally, scholars linked to service-centric approaches like SD logic, perceive service (singular), as the fundamental basis of economic exchange (Vargo \& Lusch, 2004; Vargo \& Lusch, 2008). Individual service supply chains are nested within larger value networks consisting of multiple economic actors, which are connected by information flows (Lusch et al., 2010). The conceptual boundaries of a single service supply chain are therefore difficult to define (Sampson \& Spring, 2012). Most importantly, this perspective shifts away from a supplier centric (e.g., the demarcation approach) to a holistic view that includes customers and/or other actors (Spohrer, Anderson, Pass, Ager, \& Gruhl, 2007).

While we acknowledge the importance of the debate regarding the nature of service supply chains, for this paper, we follow suggestions by Lusch et al. (2010) and Sampson and Spring (2012) and define an individual service supply chain, our unit of analysis, as one distinct component of a larger value network. As such, a single service supply chain represents an institutionalized configuration of one or multiple service providers engaging with one or multiple service customers for a common purpose. We also acknowledge that a single service supply chain represents an entire value network if no other actors are present. Value networks, however, are typically different since a single value network may consist of multiple service supply chains. Our definition thereby extends related work on service delivery networks (Tax, McCutcheon, \& Wilkinson, 2013), which explore the interactions of multiple service providers but neglect the involvement of customers. 


\section{Service supply chain formation and governance}

Existing studies in the field typically investigate mature service supply chains only (e.g. Akkermanns \& Vos, 2003; Anderson et al. 2006; Ellram et al., 2004). Therefore, empirical insights into the initial formation of service supply chains, as well as the coordination processes involved therein, are unavailable to date. This is an important gap in knowledge because the initial formation of service supply chains is suspected to determine its structure, relationships, and ability to perform (Walsh et al., 2000; Walsh \& Wellman, 2000). Thus, investigating the initial formation of service supply chains deserves additional research.

Studies focusing on goods-centric supply chains found that their formation can be motivated by new market opportunities (Holland, 1995; Stevens, 1989), the desire to gain access to resources (Kogut, 1988), or to improve the efficiency of an existing chain (Cooper \& Ellram, 1993). The goods-centric supply chain literature also discusses institutionalized coordination mechanisms as important elements with the potential to impact the formation process. These include contracts (Selviaridis \& Spring, 2010), incentive systems (Li, Chung, Goldsby, \& Holsapple, 2008), information technology (IT) and information sharing (Akkermans \& Vos, 2003), as well as relational governance mechanisms including joint decision making (Arshinder \& Deshmukh, 2008) and reputation effects (Ching, Holsapple, \& Whinston, 1996).

The service sourcing literature is related to service supply chain formation (Baltacioglu et al., 2007). Here, the debate revolves around institutionalized coordination mechanisms vs. relational governance mechanisms. While these mechanisms may be seen as substitutes, they may also be complementary (Baltacioglu et al., 2007). Institutional mechanisms (e.g., contracts) are easy to implement and alleviate risks. Relational mechanisms, however, take longer to develop, but hold the potential to lower the need for 
complicated and costly formal mechanisms through trust, commitment, and social norms (Alvarez, Pilbeam, \& Wilding, 2010). While contracts may provide a basis for openness and trust (Selviaridis \& Spring, 2010), Alvarez et al. (2010) argue that the initial formation of goods-centric supply chains relies heavily on relational, rather than formal, governance.

In summary, empirical insights in the domain in general, and findings unique to service supply chain formation in particular, remain inconclusive. The existing literature does not provide a conceptual overview of the stages of service supply chain formation and the role and types of coordination mechanisms in this process are not well understood. 


\section{Research methodology}

\section{Research objective and questions}

Our research objective is to provide theoretical and managerially relevant insights into the process of service supply chain formation and therefore to address a disciplinary research priority (Sengupta et al., 2006; Giannakis, 2010). As recommended by Eisenhardt (1989) and Perry (1998), we commenced our study by defining the following research questions:

1) How and why do service supply chains emerge?

2) How is the process of service supply chain formation coordinated?

Our research objective and questions are based on the discourse within the service research literature. Here, the importance of initially exploring how service systems operate has been acknowledged and recommended (Vargo, Maglio, \& Akaka, 2008). We therefore emphasize that our inquiry is, first, inspired by disciplinary priorities (Tracy, 2010), and second, attempts to provide both theoretical contributions as well as managerial insights.

\section{Research design}

The lack of rigorous empirical insights into coordination processes underlying service supply chain formation (Sampson \& Spring, 2012) motivated us to build theory by utilizing a casestudy design (Eisenhardt, 1989; Yin, 2009). By adopting a service-centric understanding of a service supply chain as our unit of analysis, as recommended by Lusch et al. (2010), we assume that an individual service supply chain extends beyond organizational boundaries, and is part of a larger value network. Thus, to provide a holistic understanding of our unit of analysis, it was necessary to incorporate all supply chain actors (i.e. customers) into the inquiry. Maull et al. (2012, p. 83) support this approach, as investigating the role of 
This is the post-print (i.e., final draft, post-refereeing) of the article:

Breidbach, C. F., Reefke, H., \& Wood, L. C. (2015). Investigating the formation of service supply chains. The Service Industries Journal, 35(1-2), 5-23.

customers in service supply chain coordination represents a key research priority. Since the case study method relies on multiple sources of evidence (Eisenhardt, 1989), this research method allowed us to include viewpoints from service providers and customers. We thereby address the methodological research gap highlighted by Heinonen et al. (2010), but can also triangulate our findings (Yin, 2011). Finally, opportunities for studying service supply chain formation are rare, and accurate information can only be retrieved from individuals involved in this process. Like others before us (e.g., Löfberg, Witell, and Gustafsson (2010)), we followed recommendations by Eisenhardt and Graebner (2007), and conducted our study in retrospective, thereby investigating the entire process as experienced by our participants.

\section{Case selection}

With theory-building rather than theory-testing being the purpose of this study, our case selection was motivated by the need to identify an information rich case (Eisenhardt \& Graebner, 2007). We utilized a criterion-based theoretical sampling approach (Miles \& Huberman, 1994) and, by defining the population from which a potential case could be drawn, controlled for extraneous variation, while outlining the limits within which our findings can be generalized (Eisenhardt, 1989). The population from which to select a potentially suitable case was defined as emerging institutionalized configurations of one or multiple service providers, which engage with one or multiple service customers, as components of larger value networks.

We furthermore outlined case selection criteria that ensured the observability of service supply chain formation as the phenomenon under investigation (Eisenhardt, 1989). First, we assessed if a potential case could provide access to both service provider(s) and customer(s). This was necessary to address the methodological shortcoming outlined by Heinonen et al. (2010), the research priority outlined by Maull et al. (2012), and to enable us 
to collect data from contrary viewpoints, as recommended by Yin (2011). Second, a potential case had to represent a successful instance of a newly formed service supply chain. We defined success as the chain's ability to transition from formation into a mature, steady-state operation. The criterion was motivated by our desire to identify how participants overcame potential challenges during the early stages, information which could be used to delineate managerial guidelines on how to successfully coordinate service supply chain formation.

Finally, understanding the context in which a study is situated may be just as important as case sampling (Miles \& Huberman, 1994). We selected a case in the consulting industry as this context allowed us to address our research objective and answer the research questions most appropriately. First, the link between consulting and service supply chains has been well established in the literature. For example, Anderson et al. (2006) and Giannakis (2011) highlight that consulting represents an ideal context for service supply chain research. Second, consulting depends almost entirely on effective sharing of information between consultant and customer (Bettencourt, Ostrom, Brown, \& Roundtree, 2002); this flow of information is a defining characteristic of service supply chains (Ellram et al., 2004) and larger value networks (Lusch et al., 2010). The consulting industry provides us with the opportunity to observe information flows between actors in the chain. Third, the optimal configuration of value networks has been linked to service innovation (Lusch et al., 2010). A unique property of the consulting industry, which provides further support for selecting a case in this context, is that it "constitutes the best 'laboratory' for exploring the possible specificities of innovation in services" (Gadrey \& Gallouj, 2002, p. 19).

\section{Data collection}

We collected empirical data through semi-structured interviews, field-notes, and documentation provided by the case firms. Here, we followed Yin's (2009) principles for 
collecting empirical evidence and created a case study database consisting of folders and nVivo 7 files, which included all interview transcripts and guidelines, copies of field-notes, and other documentation provided by the participants.

Our main data source were transcriptions of semi-structured interviews with representatives of the service provider and customer organizations. The semi-structured interviews were based on open-ended questions or themes, which structured each interview without constraining its course, and allowed participants to express their ideas in their own terminology (de Ruyter \& Scholl, 1998). It allowed us to probe when new or interesting themes emerged, which resulted in rich and consistent data that was insightful and represented a participant's perception, thoughts, or experiences most accurately (May, 1997).

Interviews were conducted with employees of three consulting firms and one customer firm. The consulting team consisted of two senior managers, two Project Managers, and five consultants, who were located in New Zealand, Canada, or Australia. The customer team was part of a government organization in a central Canadian province. It consisted of the division's director, here referred to as 'Project Manager', and two government employees, here referred to as 'Employee'. Interviews in New Zealand and Canada were conducted faceto-face by the same researcher, audio-recorded, and lasted approximately one hour. One interview with the Australian participant was conducted via telephone, but followed the same guidelines as the other interviews. Finally, we collected field notes to complement the interviews (Yin, 2011) and, as recommended by Eisenhardt (1989), took notes during and immediately after each interview was completed, as well as immediately after each site-visit. In addition, we collected documents such as meeting schedules, project plans, lists of teammembers, email templates, and commercial information. Table 1 provides a summary of the case. 


\section{Insert Table 1 Approximately Here}

\section{Data analysis}

Our analysis was based on recommendations outlined by Yin (2011), Miles and Huberman (1994), and Eisenhardt (1989), and was structured using Yin's (2011) phases of compiling, disassembling, and reassembling.

We compiled the data, which involved cleaning, verifying, and organizing in the software nVivo 7 (Yin 2011). Data compilation results in "stronger analyses and [...] more rigorous qualitative research" (Yin, 2011, p. 182). We cleaned and verified the data by rereading the field notes, and re-listening to the interview recordings while comparing these to the transcripts. Finally, all documents were formatted using the same font, margins, and spacing to achieve a consistent data repository.

During the second analytical phase, disassembling, two members of the research team, but not the interviewer, divided the data into individual fragments by following processes outlined in Yin (2011) and Miles and Huberman (1994). Here, we relied on contact summary sheets, which helped to summarize the main themes, issues, and insights gained from each interview (Miles \& Huberman, 1994). Furthermore, descriptive codes assigned labels to sections of data, thereby structuring the data into individual entities for further analysis (Miles \& Huberman, 1994). Finally, memoing aided the process of theory building by identifying initial relationships among clusters of codes (Yin, 2011).

Last, we introduced interpretive and pattern codes during reassembling. Our interpretive codes were more complex than descriptive codes and helped to merge individual interpretive codes into abstract units, which we classified using pattern codes (Miles \& Huberman, 1994). 


\section{The formation of a service supply chain}

\section{Research context}

Our research case consisted of three consulting firms, namely BetaStrategy, RoadConsult and AssetConsult, as well as one customer organization, BetaMinistry.

BetaStrategy is the leading consulting firm in the case and is considered one of the "Big Four" professional service and consulting firms in Canada. The organization generated revenues of US\$1.3 billion through its 30 Canadian offices in 2009. With revenues exceeding US\$ 240 million, RoadConsult employs a staff of over 2000 in New Zealand, Australia, Canada, and the UK, and consults mainly to public sector customers. AssetConsult is an engineering and management consultancy with a staff of 700 throughout several offices in North America, and specializes on condition assessment and evaluation of government buildings. BetaMinistry is a Canadian provincial government institution that manages local infrastructure assets like road and rail transportation, healthcare, and government buildings.

The service target, or purpose that drove the interaction between the consulting firms and customer, triggered the chain's formation. We found that service supply chain formation can be separated into three distinct stages: initiation, probation and operation. The story of how and why this multi-national service supply chain emerged follows these distinct stages.

\section{Initiation}

Challenges related to the management of its infrastructure assets forced BetaMinistry to increase the consistency of its asset management processes and tools. Following federal government guidelines, BetaMinistry publicly advertised a project that should result in an

Infrastructure Asset Management Framework (IAMF). However, it was also meant to provide an opportunity for governmental stakeholders to engage in learning and training : 
We were looking for a way to create a framework to help them [governmental stakeholders] move forward with asset management in a more consistent way. So we put up an RFP [Request for Proposal] looking for an infrastructure management framework.

Project Manager - BetaMinistry

BetaStrategy, the consulting firm that eventually become the leader of the service supply chain, realized the commercial potential of this project and the potential of similar value propositions in the future. After assessing its own capabilities, BetaStrategy realized that it did not possess the necessary knowledge and skills to engage with prospective government customers. BetaStrategy therefore contacted other consulting firms with complementary skill sets. Eventually, BetaStrategy gained the interest of RoadConsult and AssetConsult as additional actors for a future service supply chain. A senior manager at BetaStrategy explained the process:

Clients will say 'we need these services', so we figure out a team who has a skillset in that area, and over time if there is a growing need you bulk up in that area [....] and hence the reach out to some parties, primarily [RoadConsult], [...] and then obviously on the local engineering side [AssetConsult]. Senior Manager - BetaStrategy

The initiation of the service supply chain was driven by two factors. First, external customer demand triggered the process, which was recognized by a single service supply chain leader. Second, had BetaStrategy possessed the internal capabilities to fulfill the demand, the organization would not have attempted to incorporate other actors. Put differently, if the leading organization does not possess, or is unable to utilize, the necessary capabilities internally, external actors are included and a service supply chain emerges. We therefore propose that:

Proposition 1: Service providers are more likely to initiate the formation of service supply chains when external customer demand triggers this process, and when the required capabilities are unavailable internally. 


\section{Probation}

After the service supply chain initiation, BetaStrategy guided RoadConsult and AssetConsult in the process of creating the proposal BetaMinistry had asked for. At this stage, the newly formed service supply chain had not won the contract, nor were there any formal agreements between the organizations. BetaMinistry eventually accepted the value proposition offered by BetaStrategy, RoadConsult and AssetConsult, and perceived the group of consulting firms as one entity:

[BetaStrategy] and [RoadConsult] were the successful bidders on that [RFP]. They were, as part of the bid, a joint team. [BetaStrategy], [RoadConsult] and then [BetaStrategy] also involved [AssetConsult]. But the bid came in with all three. Project Manager -

\section{BetaMinistry}

After winning the contract, the service supply chain began its first operational iteration. The IAMF project ultimately resulted in a 400-page infrastructure asset management framework that defined the future asset management approaches within the Canadian province. However, our participants noticed that this initial project was not without its challenges, and RoadConsult worked to improve the relationships with BetaStrategy during the first operational iteration:

We sent a fellow up to assist [BetaStrategy] [...], which was a very important part of team building on this project as well, 'cause it was one of the first times we'd worked with [BetaStrategy]. Consultant - RoadConsult

Ultimately, BetaStrategy, RoadConsult, and AssetConsult all understood that the IAMF project was merely a 'test case' that, if completed successfully, could lead to a stable service supply chain. The successful completion of the IAMF project can therefore be described as a probation stage, which helped all actors to evaluate their roles and confirmed the desire to maintain the service supply chain. The IAMF project provided the necessary 
commercial validation, and BetaStrategy, RoadConsult, and AssetConsult subsequently decided to follow their original intention to establish a permanent service supply chain. AssetConsult's Project Manager describes the scenario:

The [IAMF project] was very successful, because it created this relationship between [RoadConsult], [AssetConsult] and [BetaStrategy]. We worked on that one project for [BetaMinistry] and there were two projects that fell out of it, that the three of us worked again together on those, and those were much larger. Project Manager - AssetConsult

During the time of our interviews, the service supply chain had recently completed two additional iterations using this initial configuration and had plans for future collaborations using the same configuration. We therefore argue that the sustainability of a service supply chain, here defined as its ability to operate on an ongoing basis, is contingent on success during the probation stage. We propose:

Proposition 2: Service supply chains are more likely to be sustainable if the probation stage is completed successfully.

\section{Operation}

After the successful completion of the probation stage, the service supply chain did not fall back into another initiation stage by adding new actors, but continued to operate in its existing configuration. Our participants explained that the chain subsequently operated more efficiently due to the high degree of familiarity and trust established between its actors:

We knew we had a bit of an advantage [...]. Having worked on three assignments already together, of course, you know the people that you work with, if you trust them, they're reliable, and cooperative with you, then sure, you'd want to work with them again. And all three projects that I've ever done with the team were great. Project

\section{Manager - AssetConsult}


While a successful probation stage appears to be crucial when attempting to achieve sustainability in a new service supply chain, our findings indicate that the efficiency of ongoing interactions may be crucial when maintaining a newly formed service supply chain. While each iteration involved different customers, the service supply chain itself did not require re-configuration. This level of stability could be attributed to functioning interpersonal relationships. We therefore propose:

Proposition 3: Service supply chains are more likely to remain sustainable, and will not require re-configuration, if mutual levels of trust and relationships between individual human actors can be preserved.

The initial formation of the service supply chain and the development of interpersonal working relationships between individual actors within the service supply chain were created and managed through a variety of coordination mechanisms. We subsequently highlight the coordination mechanisms inherent in each formation stage that relate to the service provider, customer, or both. 


\section{Coordination mechanisms in service supply chain formation}

The case at hand allowed us to identify which coordination mechanisms were used to coordinate the formation of the service supply chain, and to link these to the individual stages of initiation, probation and operation. The coordination mechanisms we identified include institutions, governance and information management. Figure 1 provides an overview.

\section{Insert Figure 1 Approximately Here}

\section{Institutions}

Institutions were explicitly defined by the service supply chain and enabled all actors to engage in an effective and efficient fashion throughout the chain's formation. Specifically, we identified the Project Manager and Service Supply Chain Manager as such coordination mechanisms, both of which were performed by the service providers.

\section{Project Manager}

The Project Manager was responsible for the billing aspects of the service supply chain and set the groundwork in terms of expectations amongst the consulting companies. However, the Project Manager did not support the technical content or the final output, which was entirely the domain of the Service Supply Chain Manager. Our data highlights explicit differences in regard to the frequency by which the Project Manager and Service Supply Chain Manager interacted with others. For example, the Project Manager sent 145 emails during the formation of the service supply chain, while the Service Supply Chain Manager sent over 1,200 emails.

\section{Service Supply Chain Manager}

The Service Supply Chain Manager played a particularly prominent role during the probation 
stage of the service supply chain. Since the consultants were located in New Zealand, Australia and Canada, RoadConsult recognized the necessity to institutionalize a coordination mechanism that would orchestrate their interaction with the customer, BetaMinistry. The Service Supply Chain Manager therefore allocated tasks amongst the consultants by taking overall responsibility of the technical output:

I drop into a project team and sit alongside the project-manager, but don't deal with the day-to-day billing aspects of the project. I am responsible for the overall technical outputs $[\ldots]$. We had 3 different consulting firms and my role was to $[\ldots]$ take the overall authorship of the final report. Service Supply Chain Manager - RoadConsult

Task allocation proved particularly challenging, since his role did not exert any control over the other consultants, and was based on technology-enabled exchanges only.

I didn't have aligned [...] control of any of them [consultants]. There wasn't a single person I could just dictate and say "do this." Most of them were not in my company, [RoadConsult], and by and large they were all equals in terms of position [...]. Just on emails, I sent around 1200 emails [John], the Project Manager, sent 145. I received 2000, but it was my role to make sure that all [consultants] were working together. Service Supply Chain Manager - RoadConsult

The Service Supply Chain Manager's capacity to coordinate the interaction along the service supply chain was contingent on his ability to engage with the employees of BetaMinistry through regular face-to-face meetings. The other employees of RoadConsult, AssetConsult and BetaStrategy were not able to do so due to their global distribution. Therefore, the entire interaction between the wider group of consultants and the employees of BetaMinistry was channeled through the Service Supply Chain Manager. The importance of this institutionalized coordination mechanism was even recognized by BetaMinistry:

[The Service Supply Chain Manager] was such a people person [...]. I felt that I was being well served by the team [of consultants] because I was being well served by [the Service Supply Chain Manager]. I didn't care that I didn't see [the employees of 
RoadConsult] once in my life, but I knew that [...] what I said to [the Service Supply

Chain Manager], was reflected in whatever [the employees of RoadConsult] turned in.

Employee - BetaMinistry

By implementing multiple, yet distinctly different institutions as coordination mechanisms, the inherent complexity of the interactions between the actors of a service supply chain could be reduced. At the same time, the likelihood for success in the probation stage increases. This is important since, as highlighted by our Proposition 2, success during the probation stage can be considered an antecedent to an operational and sustainable service supply chain. We therefore propose:

Proposition 4: Service supply chains that reduce the complexity of interactions between its actors by implementing institutionalized coordination mechanisms are more likely to successfully complete the probation stage.

\section{Governance}

As a coordination mechanism, governance incorporates activities that aim to coordinate the formation of the service supply chain. Unlike the institutions, which focus predominantly on interactions amongst the various service providers, governance mechanisms explicitly include the customers as well. We identified Relationship Management and Engagement Management as the two central governance mechanisms.

\section{Relationship management}

Establishing interpersonal working relationships between globally distributed consultants (i.e., between the individual employees of the different service providers of the service supply chain), was challenging, though considered crucial for the effectiveness of their interactions by the Service Supply Chain Manager. Relationship management included two central tasks. First, to establish interpersonal working relationships between the employees of 
RoadConsult, BetaStrategy, and AssetConsult during the initiation stage of the service supply chain. Second, to support the ongoing management of these relationships during the probation and operation stages. A 'kick-off' meeting was used to establish these relationships between consultants, who then continued to collaborate remotely:

At the very beginning of the project we had a start-up team building session [...] where we brought together all the team members, very useful, I'd say that was probably a big factor in the success of the project. [....] a lot of these people were just meeting for the first time, and it was a good opportunity to put a face to the person, so that when you had subsequent conversations, be it e-mail or telephone, you already had a relationship established. Consultant - RoadConsult

While the face-to-face kick-off was pivotal during the initiation stage, the newly established relationships had to be managed during the chain's probation and, to a lesser extent, during the operation stage. Specifically, we found that behavioral patterns like the responsiveness and reliability of an individual consultant during IT-enabled exchanges were crucial when managing interpersonal working relationships and trust with others:

\footnotetext{
Responsiveness, that's one way to gain trust. You know that someone is reliable and that you can trust them [...] I have to say responsiveness is at the top of the list, assuming technical competence is a given. And responsiveness, to just communication, whether it's email, or telephone, or whatever it is. You're submitting things as required, you're meeting your schedule for deliverables. Project Manager - BetaStrategy
}

The ability of an individual actor in a service supply chain to manage interpersonal relationships had a positive impact on his or her reputation. This resulted in increased levels of trust between the consultants, allowed for a more seamless workflow, and eased the need of the Service Supply Chain Manager to coordinate tasks, as these could be self-organized.

\section{Engagement management}

While 'relationship management' was centered on the service providers (i.e., BetaStrategy, 
RoadConsult and AssetConsult), the interactions with the service customer BetaMinistry had to be coordinated as well. We refer to this coordination mechanism as 'engagement management'. Engagement management focuses on involving and educating the customer during the probation and operation stages of the service supply chain formation. Specifically, this process increased the customer's awareness of the importance of providing relevant input and information to the consultants. While simple in concept, the willingness of some employees of BetaMinistry to provide such information was lacking:

You're heavily reliant on extracting information from the client and educating the client.

\section{Consultant - RoadConsult}

Subsequently, the Service Supply Chain Manager ensured the cooperation of customer employees by associating them with the IAMF project during the probation stage:

Look at the front cover of the report. As soon as people [employees of BetaMinistry] saw that their name was on the project, it gave them buy-in, because they realized that they were associated with the project. A lot of people didn't necessarily give a lot of buy-in $[\ldots]$ but $[\ldots]$ as soon as you put someone's name to something, they suddenly have an obligation to make it work. Service Supply Chain Manager - RoadConsult

As coordination mechanisms, the Project Manager and Service Supply Chain Manager represent institutionalized actors who coordinate the formation of service supply chains. Governance mechanisms, however, are activities, performed to establish, manage, and improve the strength of interpersonal working relationships between the chain's actors. As relationship management increased the levels of trust between actors during formation it is directly relevant to the ability of a service supply chain to remain sustainable (see Proposition 3). Engagement management had a similar effect, and ensured ongoing access to the critical resource information. We therefore propose: 
Proposition 5: Service supply chains that effectively utilize the governance mechanisms of relationship and engagement management will improve interpersonal working relationships, experience higher levels of trust between its actors and thereby improve their ability to exchange information.

\section{Information management}

The quality of interpersonal relationships in the service supply chain was also contingent on its ability to effectively manage technology-enabled interactions. Information management is a distinct coordination mechanism that ensures this ability. Our participants linked the effectiveness of their exchanges to, once again, established interpersonal relationships and thereby to the coordination mechanism of relationship management. Specifically, interpersonal relationships led to less formal, and hence more efficient, technology-enabled interactions:

I think it [interactions] could just be a more... perhaps not as formal; it could be a little more informal, more direct. Given the sterile nature of emails to begin with, when you've met somebody and you've heard their voice, and know a little bit what they're like [...]. It's enough to break the ice and establish some type of a relationship. I think when you read e-mails and respond e-mails you do it in a different way. Consultant - RoadConsult

Ultimately, effectively managing interpersonal relationships becomes crucial for the performance of the chain, as established interpersonal relationships increase the effectiveness and efficiency of technology-enabled exchanges. Our final proposition indicates that:

Proposition 6: Service supply chains with established and maintained interpersonal relationships between its actors are more likely to experience effective and efficient technology-enabled information exchanges. 


\section{Discussion}

\section{Theoretical implications}

This study addresses the call for empirical research on service supply chains that emerged as a disciplinary priority in the wider service management literature (Sengupta et al., 2006; Giannakis, 2010; Sampson \& Spring, 2012). We adopted a service centric perspective, as called for by Lusch et al. (2010) and Breidbach et al. (2011), to study service supply chain formation and the coordination mechanisms inherent in this process. By exploring the role and input of service customers and service providers, we address methodological shortcomings in service research more broadly (Heinonen et al., 2010), and address specific research priorities in service supply chain research (Maull et al., 2012). As such, this study extends firm-centric studies that typically attempt to transfer insights from traditional supply chain studies into service research by assuming the existence of a mature service supply chain (Frohlich \& Westbrook, 2002; Akkermans \& Vos, 2003; Ellram et al., 2004), and also contributes to the service sourcing literature (e.g., Allen \& Chandrashekar, 2000; Baltacioglu et al., 2007; McIvor, 2010).

By drawing on findings from a case study conducted in the context of the consulting industry, we showed how and why a service supply chain is initially formed and how this process is supported through the use of appropriate coordination mechanisms. The inductive theory building process underlying this study enabled us to provide a theoretical and empirical contribution to the wider service management, service sourcing, and service supply chain literature through a set of propositions and a conceptual model. To the best of our knowledge, we provide the first empirical insights into the initial stages of service supply chain formation, and link these insights to the coordination mechanisms inherent in each stage. Based on our data set, Figure 2 summarizes our assessment of the stages underlying 
service supply chain formation and the coordination mechanism utilized within each stage.

\section{Insert Figure 2 Approximately Here}

The successful formation of a service supply chain can be separated into the distinct stages of initiation, probation, and ongoing operation. Actors utilize a variety of governance mechanisms to coordinate this process, including institutions, governance and information management.

Through proposition 1, we showed that customer demand triggers service supply chain formation whenever individual service providers, who recognize the demand, do not possess the necessary knowledge and skills internally to meet the demand. This finding is supported by the work of Holland (1995) and Stevens (1989), who found that supply chain initiation is triggered by customer demand (e.g., by new market opportunities). Furthermore, our findings support Kogut (1988), who argues that the desire to gain access to external resources (i.e., the capabilities of potential service supply chain partners), motivates (service) supply chain formation.

Unlike Kogut (1988), Stevens (1989), or Holland (1995), we provide insights that reach beyond the motivations to form service supply chains. Specifically, we found that success during the subsequent probation stage is crucial when attempting to build a service supply chain that can be sustained and operated on an ongoing basis, and expressed this finding through our proposition 2. We thereby extend the work by Walsh and Wellman (2000) and Walsh et al. (2000), who argue that the initial formation (i.e., the initiation stage) determines the future performance of a (service) supply chain. Specifically, success during the probation stage appears to be crucial for the future performance of a service supply chain. Consequently, the following question arises: How can actors in newly formed service supply chains ensure that the probation stage is completed successfully? 
The probation stage represents the first instance when all actors of the newly formed service supply chain interact with one another. Through proposition 4 and proposition 5 , we indicated that the complexity of these interactions could be reduced through a variety of coordination mechanisms. We did not encounter institutionalized coordination mechanisms like incentive systems (Li et al., 2008) or contracts (Arshinder \& Deshmukh, 2008; Selviaridis \& Spring, 2010) which are commonly mentioned in the traditional supply chain literature. However, we found that, as coordination mechanisms, actors (i.e., the Project Manager and Service Supply Chain Manager) direct the formation of service supply chains through activities, which establish, manage, and improve the strength of interpersonal working relationships within a new service supply chain. Interactions between service supply chain actors and access to information can be improved by enhancing interpersonal working relationships between all actors (e.g., with relationship management or engagement management); thus, coordination mechanisms relating to governance improve access to information. This makes a newly initiated service supply chain more likely to succeed in the probation stage. While this finding may be related to reputation effects (Ching et al., 1996), as a type of relational coordination mechanism, we found that the perception of an individual actor, or their reputation, is a consequence of governance mechanisms, rather than a coordination mechanism in itself. The activity of relationship management where physically distributed actors of the service supply chain were brought together for 'kick-off' workshops at the beginning of the probation stage can be linked to findings originating in the virtual team literature. Here, Majchrzak et al. (2000) argue that face-to-face interactions improve the performance of virtual teams because they, among other aspects, help to establish a common terminology amongst team members.

Consistent with Bettencourt et al. (2002), we found that access to customer information was considered crucial to success. However, contrary to Vargo, Lusch and 
Akaka, who argue that "all actors involved in [a service] exchange are relational, and thus openly share relevant information" (2010, p. 150), the service providers in our study struggled to accesses the necessary quantity and quality of information from BetaMinistry. Previous work by Möller indicates that customers "might lack the willingness" (2008, p. 206) to share information in service processes. While such connective gaps (Breidbach, Srinivasan $\&$ Kolb, 2013), may potentially jeopardize the success of the service supply chain's probation stage, Möller (2008) suggests that service firms could utilize non-professional socializing to enhance the willingness of customers to share information. This was not supported by our findings. The Service Supply Chain Manager, however, publicly associated senior members of BetaMinistry with the IAMF project, thereby ensuring their support.

Finally, we found the service supply chain could avoid its re-configuration during the operation stage if mutual levels of trust and relationships could be maintained between the service providers (highlighted through our proposition 3). Through proposition 6 , we showed that the effectiveness and efficiency of technology-enabled information exchanges increases whenever a service supply chain maintains interpersonal relationships between its actors. As such, our findings do not support the argument that ICTs themselves are central coordination mechanisms (Akkermans \& Vos, 2003; Arshinder \& Deshmukh, 2008). However, Mithas, Ramasubbu, and Sambamurthy (2011) argue that a firm's customer management capabilities mediate the impact of information management on firm performance. While Mithas et al. (2011) focus on a single firm rather than the inter-firm exchanges that occur in service supply chains, we emphasize that effective IT-enabled inter-firm exchanges support the development of sustainable service supply chains. In our study we were not able to discern whether this was mediated by interpersonal relationships only. 
Another question that remains unresolved is whether institutionalized coordination mechanisms are more important than relational ones. Overall, the service sourcing literature appears to favor institutionalized mechanisms; e.g., contractual negotiations (McIvor, 2010) and clearly defined performance expectations (Allen \& Chandrashekar, 2000). We broadly agree with Alvarez et al. (2010), in that initial service supply chain formation relies on relational, rather than institutionalized coordination mechanisms. More specifically though, we believe it is necessary to extend the work by Alvarez et al. (2010), and argue that provider-customer interaction and coordination must be treated as distinct from providerprovider interactions. While interactions between the service providers and customer were highly formal throughout the initiation stage, interactions amongst the various service providers were, at the same time, informal and relational. However, by building on the work of Lindberg and Nordin (2008), we argue that the operation stage of a service supply chain may be perceived as iterative and dynamic. As such, the individual value propositions offered by the chain should become increasingly objectified (Lindberg \& Nordin, 2008); i.e., increasingly routinized and standardized. Therefore, we may see greater use of institutional rather than relational coordination mechanisms amongst the service providers in the service supply chain once it matures into a steady state.

\section{Managerial implications}

Forming a service supply chain can provide a strategic advantage to service providers, especially when access to new knowledge and skills is crucial. However, understanding how to initiate and coordinate this process likely remains an unfamiliar challenge to many.

While success during the initiation stage is largely contingent on the customer, managing success during the probation stage can be controlled and lead to a sustainable service supply chain. We suggest implementing the Service Supply Chain Manager as a 
This is the post-print (i.e., final draft, post-refereeing) of the article:

Breidbach, C. F., Reefke, H., \& Wood, L. C. (2015). Investigating the formation of service supply chains. The Service Industries Journal, 35(1-2), 5-23.

distinctly different role from the Project Manager. Furthermore, both service provider(s) and customer(s) need to embrace the fact that managing interpersonal relationships between all actors of the service supply chain is crucial. We highlighted a number of effective approaches, but emphasize that initiating relationships through face-to-face meetings is a particularly effective approach. While BetaStrategy conducted such an event for its consultants only, we suggest customers should equally be included in this process as it would likely ensure continued access to information in cases where the Service Supply Chain Manager may be unavailable.

ICTs can, in conjunction with appropriate relationship-building exercises, increase the effectiveness of service supply chain operation. Of course, utilizing ITs is not, in itself, an adequate coordination mechanism. However, relationship management and information management can be supplementary coordination mechanisms; relationship management increases the effectiveness of IT-enabled information exchanges, which is crucial for service supply chains with physically dispersed actors.

Finally, we encourage managers to familiarize themselves with the potential challenges associated with customer dependency. While gathering input information from customers is essential, individual customers may be reluctant to provide this resource. One approach to overcome this challenge may be to associate key employees of the service customer with the proposed outputs, to ensure their support.

\section{Limitations and future research}

Any potential limitation of this study should be viewed in light of the decisions we made while conducting it (Leonard-Barton, 1990). Specifically, the retrospective nature of the case and context dependency are potential limitations. 
Eisenhardt and Graebner (2007) recommend investigating cases in retrospective when interviews represent the main source of evidence, as was the situation in our study. While common in service research (Breidbach, et al., 2013), collecting data retrospectively was not without challenges since participants had to rely on their memory. We subsequently applied Eisenhardt and Graebner's (2007) suggestions to mitigate such potential risks by interviewing participants from various hierarchies, groups, and geographies.

We conducted this study in the context of the consulting industry, as recommended in the literature, but cannot argue that our findings are context independent. Rather, we emphasize that this work provides analytic generalization through inductive theory building, rather than statistical generalization. As such, we offer unique insights into the characteristics and mechanisms of service supply chain formation in the context of the consulting industry and provide avenues for future research.

We do see ample potential for future longitudinal case studies investigating service supply chain formation, from its initiation through to ongoing operation and beyond. We acknowledge that such an undertaking is extremely time consuming and contingent on access to industry partners. Furthermore, moving the focus away from the service supply chain as the unit of analysis, to individual actors within a chain, presents a significant opportunity for future enquiries. Carter, Kaufmann, and Michel (2007) provide early conceptual insights, but our understanding of the mechanisms influencing the behavior and decision making processes of internal stakeholders remains limited. Specifically, we suggest that future scholars could investigate potential hierarchical effects between senior and junior staff members, and provide empirical insights into how these effects may influence the formation and performance of service supply chains. 
Understanding the impact of inter-organizational learning on service supply chain performance provides equally important future research avenues. Some scholars proposed that supply chain learning should be facilitated across multiple stages (i.e., from set-up to sustained operation) to be effective (Bessant, 2004). Since we focused on initial service supply chain formation, the ongoing performance implications of inter-organizational learning could not be explored. Specifically, the insights into 'the human element' underlying service supply chains that we provide are considered to be elemental to effective learning processes (Bessant, 2004). Hence, amongst many other questions, scholars could study how learning within a single service supply chain influences the entire value network.

A final question that emerges from this research is linked to the role of contracts as a coordination mechanism. While contracts have previously been discussed as a means to coordinate goods-centric supply chains (Arshinder \& Deshmukh, 2008; Selviaridis \& Spring, 2010), issues of confidentiality prohibited us from accessing such documentation. Future research may find ways to access such data and provide a deeper understanding into the role of contracts as a coordination mechanism in the context of service supply chains. 


\section{References}

Akkermans, H., \& Vos, B. (2003). Amplification in service supply chains: An exploratory case study from the telecom industry. Production and Operations Management, 12(2), 204-223.

Allen, S., \& Chandrashekar, A. (2000). Outsourcing services: The contract is just the beginning. Business Horizons, 43(2), 25-34.

Alvarez, G., Pilbeam, C., \& Wilding, R. (2010). Nestlé Nespresso AAA sustainable quality program: An investigation into the governance dynamics in a multi-stakeholder supply chain network. Supply Chain Management, 15(2), 165-182.

Anderson, E. G., Morrice, D. J., \& Lundeen, G. (2006). Stochastic optimal control for staffing and backlog policies in a two-stage customized service supply chain. Production and Operations Management, 15(2), 262-278.

Arshinder, K. A., \& Deshmukh, S. G. (2008). Supply chain coordination: Perspectives, empirical studies and research directions. International Journal of Production Economics, 115(2), 316-335.

Baltacioglu, T., Ada, E., Kaplan, M. D., Yurt, O., \& Kaplan, Y. C. (2007). A new framework for service supply chains. The Service Industries Journal, 27(2), 105-124.

Bessant, J. (2004). Supply chain learning. In S. New \& R. Westbrook (Eds.), Understanding supply chains: Concepts, critiques and futures (pp. 165-190). Oxford, UK: Oxford University Press.

Bettencourt, L. A., Ostrom, A. L., Brown, S. W., \& Roundtree, R. I. (2002). Client coproduction in knowledge-intensive business services. California Management Review, 44(4), 100-128. 
Breidbach, C. F., Kolb, D. G., \& Srinivasan, A. (2013). Connectivity in service systems: Does technology-enablement impact the ability of a service system to co-create value? Journal of Service Research, 16(3), 428-441.

Breidbach, C. F., Reefke, H., \& Wood, L. C. (2011). Service supply chain management: Research implications from the Service-Dominant Logic. In 9th ANZAM Operations, Supply Chain and Services Management Symposium (pp. 160-184). Deakin University, Geelong, Australia.

Carter, C. R., Kaufmann, L., \& Michel, A. (2007). Behavioral supply management: A taxonomy of judgment and decision-making biases. International Journal of Physical Distribution \& Logistics Management, 37(8), 631-669.

Ching, C., Holsapple, C. W., \& Whinston, A. B. (1996). Toward IT support for coordination in network organizations. Information \& Management, 30(4), 179-199.

Cooper, M. C., \& Ellram, L. M. (1993). Characteristics of supply chain management and the implications for purchasing and logistics strategy. International Journal of Logistics Management, 4(2), 13-24.

de Ruyter, K., \& Scholl, N. (1998). Positioning qualitative market research: Reflections from theory and practice. Qualitative Market Research, 1(1), 7-14.

Eisenhardt, K. M. (1989). Building theories from case study research. Academy of Management Review, 14(4), 532-550.

Eisenhardt, K. M., \& Graebner, M. E. (2007). Theory building from cases: Opportunities and challenges. Academy of Management Journal, 50(1), 25-32.

Ellram, L. M., Tate, W. L., \& Billington, C. (2004). Understanding and managing the services supply chain. Journal of Supply Chain Management, 40(4), 17-32.

Frohlich, M. L., \& Westbrook, R. (2002). Arcs of integration: An international study of supply chain strategies. Journal of Operations Management, 19(2), 185-200. 
Gadrey, J., \& Gallouj, F. (Eds.). (2002). Productivity, innovation and knowledge in services: New economic and socio-economic approaches. Cheltenham, UK: Edward Elgar. Giannakis, M. (2010). Conceptualizing and managing service supply chains. The Service Industries Journal, 31(11), 1809-1823.

Giannakis, M. (2011). Management of service supply chains with a service-oriented reference model: The case of management consulting. Supply Chain Management, 16(5), 346361.

Heinonen, K., Strandvik, T., Mickelsson, K. -J., Edvardsson, B., Sundstrom, E., \& Anderson, P. (2010). A customer-dominant logic of service. Journal of Service Management, 21(4), 531-548.

Holland, C. P. (1995). Cooperative supply chain management: The impact of interorganizational information systems. The Journal of Strategic Information Systems, 4(2), 117-133.

Kogut, B. (1988). Joint ventures: Theoretical and empirical perspectives. Strategic Management Journal, 9(4), 319-332.

Leonard-Barton, D. (1990). A dual methodology for case studies: Synergistic use of a longitudinal single site with replicated multiple sites. Organization Science, 1(3), 248266.

Li, X., Chung, C., Goldsby, T. J., \& Holsapple, C. W. (2008). A unified model of supply chain agility: The work-design perspective. International Journal of Logistics Management, 19(3), 408-435.

Lindberg, N., \& Nordin, F. (2008). From products to services and back again: Towards a new service procurement logic. Industrial Marketing Management, 37(3), 292-300.

Löfberg, N., Witell, L., \& Gustafsson, A. (2010). Service strategies in a supply chain. Journal of Service Management, 21(4), 427-440. 
Lovelock, C. H., \& Gummesson, E. (2004). Whither services marketing? In search of a new paradigm and fresh perspectives. Journal of Service Research, 7(1), 20-41.

Lusch, R. F., Vargo, S. L., \& Tanniru, M. (2010). Service, value networks and learning. Journal of the Academy of Marketing Science, 38(1), 19-31.

Majchrzak, A., Rice, R. E., Malhotra, A., King, N., \& Ba, S. (2000). Technology adaptation: The case of a computer-supported inter-organizational virtual team. MIS Quarterly, 24(4), 569-600.

Maull, R., Geraldi, J., \& Johnston, R. (2012). Service supply chains: A customer perspective. Journal of Supply Chain Management, 48(4), 72-86.

May, T. (1997). Social research: Issues, methods and process (2nd). Buckingham, UK: Open University Press.

McIvor, R. (2010). Global services outsourcing. Cambridge, UK: Cambridge University Press.

Miles, M. B., \& Huberman, A. M. (1994). Qualitative data analysis: An expanded sourcebook (2nd ed.). Thousand Oaks, CA: Sage.

Mithas, S., Ramasubbu, N., \& Sambamurthy, V . (2011). How information management capability influences firm performance. MIS Quarterly, 35(1), 237-256.

Möller, S. (2008). Customer integration - A key to an implementation perspective of service provision. Journal of Service Research, 11(2), 197-210.

Perry, C. (1998). Processes of a case study methodology for postgraduate research in marketing. European Journal of Marketing, 32(9/10), 785-802.

Sampson, S. E., \& Spring, M. (2012). Customer roles in service supply chains and opportunities for innovation. Journal of Supply Chain Management, 48(4), 30-50. 
Selviaridis, K., \& Spring, M. (2010). The dynamics of business service exchanges: Insights from logistics outsourcing. Journal of Purchasing and Supply Management, 16(3), 171-184.

Sengupta, K., Heiser, D. R., \& Cook, L. S. (2006). Manufacturing and service supply chain performance: A comparative analysis. Journal of Supply Chain Management, 42(4), 4-15.

Spohrer, J., Anderson, L. C., Pass, N. J., Ager, T., \& Gruhl, D. (2007). Service science. Journal of Grid Computing, 6(3), 313-324.

Stevens, G. C. (1989). Integrating the supply chain. International Journal of Physical Distribution \& Logistics Management, 19(8), 3-8.

Tax, S. S., McCutcheon, D., \& Wilkinson, I. F. (2013). The service delivery network (SDN): A customer-centric perspective of the customer journey. Journal of Service Research, $16(4), 454-470$.

Tracy, S. J. (2010). Qualitative quality: Eight "big tent" criteria for excellent qualitative research. Qualitative Inquiry, 16(10), 837-851.

Vandermerwe, S., \& Rada, J. (1988). Servitization of business: Adding value by adding services. European Management Journal, 6(4), 314-324.

Vargo, S. L., \& Lusch, R. F. (2004). Evolving to a New Dominant Logic for Marketing. Journal of Marketing, 68(1), 1-17.

Vargo, S. L., \& Lusch, R. F. (2008). From goods to service(s): Divergences and convergences of logic. Industrial Marketing Management, 37(3), 254-259.

Vargo, S. L., Maglio, P. P., \& Akaka, M. A. (2008). On value and value co-creation: A service systems and service logic perspective. European Management Journal, 26(3), $145-152$. 
Vargo, S. L., Lusch, R. F., \& Akaka, M. A. (2010). Advancing service science with servicedominant logic. In P. P. Maglio, C. A. Kieliszewski \& J. Spohrer (Eds.), Handbook of Service Science (pp. 133-156). Berlin, Germany: Springer.

Walsh, W. E., \& Wellman, M. P. (2000). Modeling supply chain formation in multiagent systems. In A. Moukas, F. Ygge, \& C. Sierra (Eds.), Agent Mediated Electronic Commerce II (pp. 94-101). Berlin/Heidelberg, Germany: Springer.

Walsh, W. E., Wellman, M. P., \& Ygge, F. (2000). Combinatorial auctions for supply chain formation. $2^{\text {nd }}$ ACM Conference on Electronic commerce - EC '00. pp. 260-269.

Yin, R. K. (2009). Case study research: Design and methods (4th ed.). Thousand Oaks, CA: Sage.

Yin, R. K. (2011). Qualitative research from start to finish. London, UK: Guilford Press. Youngdahl, W. E., \& Loomba, A. P. S. (2000). Service-driven global supply chains. International Journal of Service Industry Management, 11(4), 329-347.

Zeithaml, V. A., Parasuraman, A., \& Berry, L. (1985). Problems and strategies in services marketing. Journal of Marketing, 49(2), 33-46. 